\title{
Motion via Art
}

\section{Abraham Tamir*}

Ben Gurion University of the Negev, Beer Sheva, Israel

Submitted: November 23, 2017; Published: December 04, 2017

*Corresponding author: Abraham Tamir, Ben Gurion University of the Negev, Beer Sheva, Israel, Tel: +972 86461600; Email: atamir4@012.net.il

\section{Short Communication}

Motion is one of the key topics in physics that is related to the change in position of an object with respect to time. It is typically described in terms of velocity, acceleration, displacement and time. Everything in the niverse moves. It might only be a small amount of movement and very slow, but movement does happen. Don't forget that even if you appear to be standing still, the Earth is moving around the Sun, and the Sun is moving around our galaxy. The movement never stops. Motion is one part of what physicists call mechanics. Over the years, scientists have discovered several rules or laws that explain motion and the causes of changes in motion. It was Newton who said that the motion of objects could be fully described by only three laws that were also formulated by him in the $17^{\text {th }}$ century. In the following the motion phenomenon will be described by art.

The first motion in the universe was that of light. This is mentioned in Genesis 1.3: And God said, "Let there be light, and there was light" that moved from its creation point throughout the entire space of the universe. Figure 1 entitled "The Creation Duel" demonstrates artistically the above phenomenon. Probably, the most widespread motion is related to the pupil of our eyes. Depending on the looking situation, motion of the pupils between five positions is possible as demonstrated in Figure 2. A very widespread situation is that of "no motion" as demonstrated in Figure 3 painted by Fernando Botero, a Colombian artist. In general there are five types of motion. "Linear motion" is that of moving along a straight line is demonstrated (Figure 4-6). Figure 4 is a sculpture made by the Swiss sculptor and painter Alberto Giacometti. Figure 5, demonstrating motion due to gravity, is an artwork made by Rene Magritte, Belgium Surrealist where the English photographer Eadweard J. Muybridge produced Figure 6 . The picture installed at the center of the figure was painted by the Israeli artist Orly Lancet Joseph. Another kind of motion is "Reciprocating motion" that is moving backwards and forwards in a straight line as demonstrated in Figure 7. An additional kind of motion is "Rotary motion" in which there is turning round in a circle, such as a wheel turning Figure 8. This motion is demonstrated by the artwork of the Israeli artist David Gerstein. Figure 9 demonstrates "Oscillating motion" that is a swinging from side to side, like a pendulum in a clock. It was painted by Man Ray, an American artist. "Periodic or cyclic motion" that is any motion which repeats itself is demonstrated in Figure 10 painted by M.C.Escher, a Dutch graphic surrealist artist. An insight look at the artwork reveals endless stairs that are the main motif of it practically impossible. Figure 11, "Waterfall", painted by Escher describes "Perpetual motion" characterized by a hypothetical machine that operate or produce useful work indefinitely. Here water is flowing upwards without investing any energy. And finally Figure 12 demonstrates an illusion of motion due to the continuous change in the size of the squares.

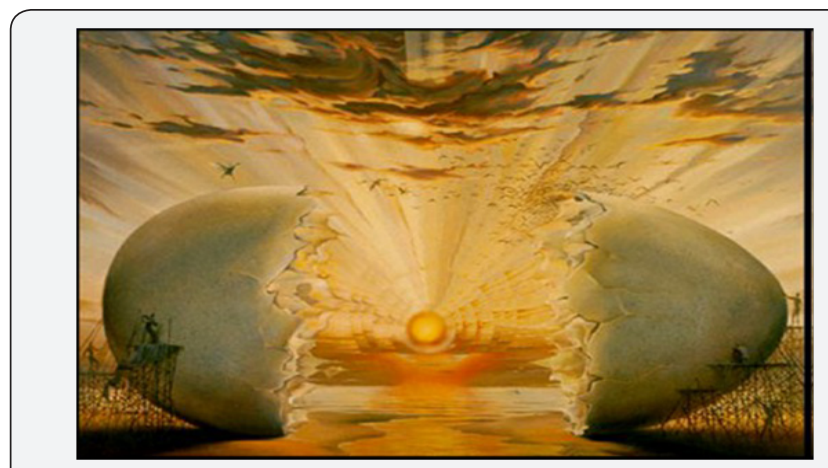

Figure 1: The Creation Duel.

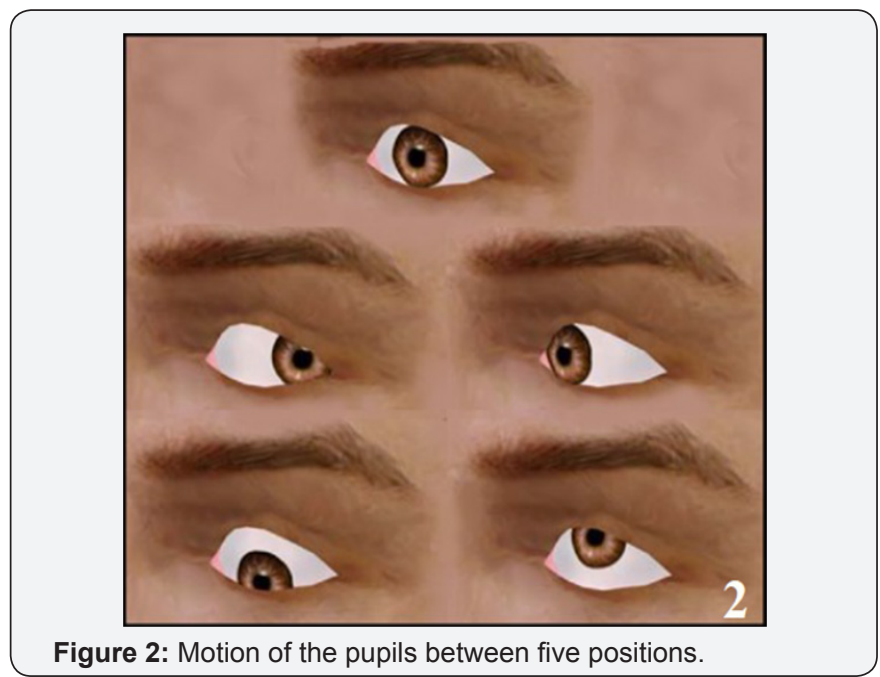




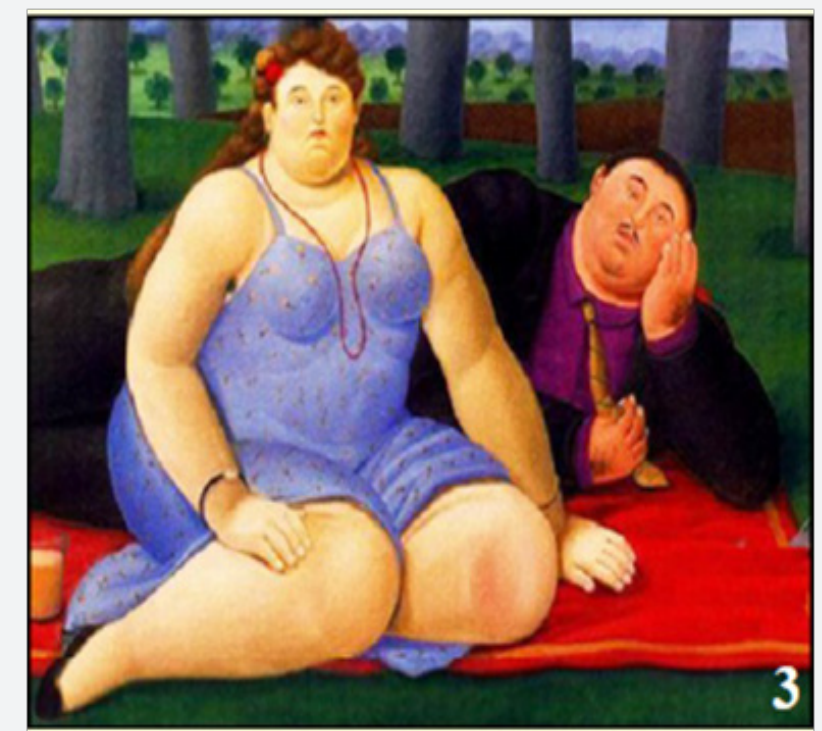

Figure 3: No motion.

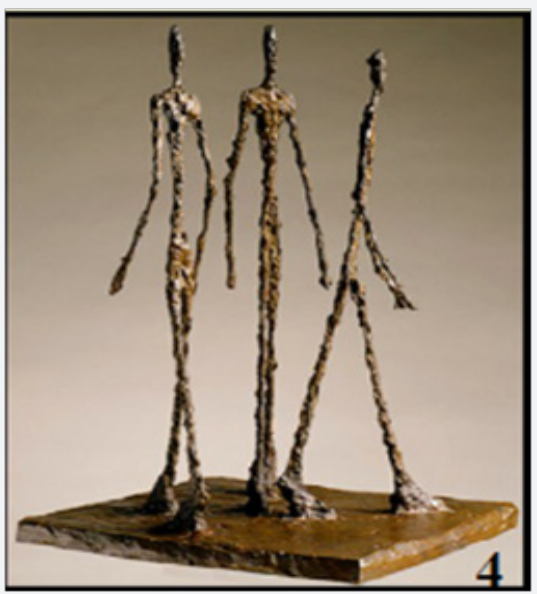

Figure 4: Linear motion

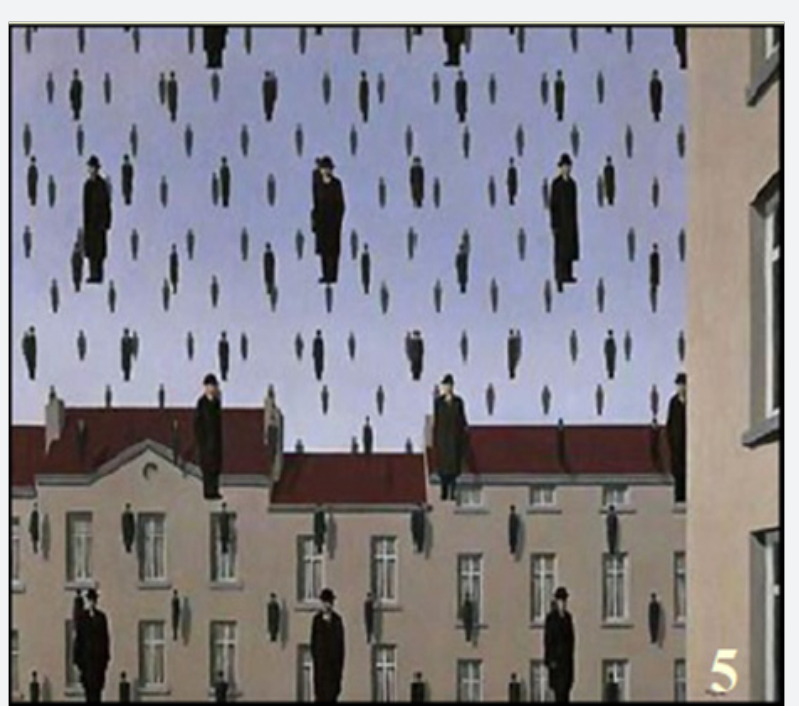

Figure 5: Motion due to gravity.

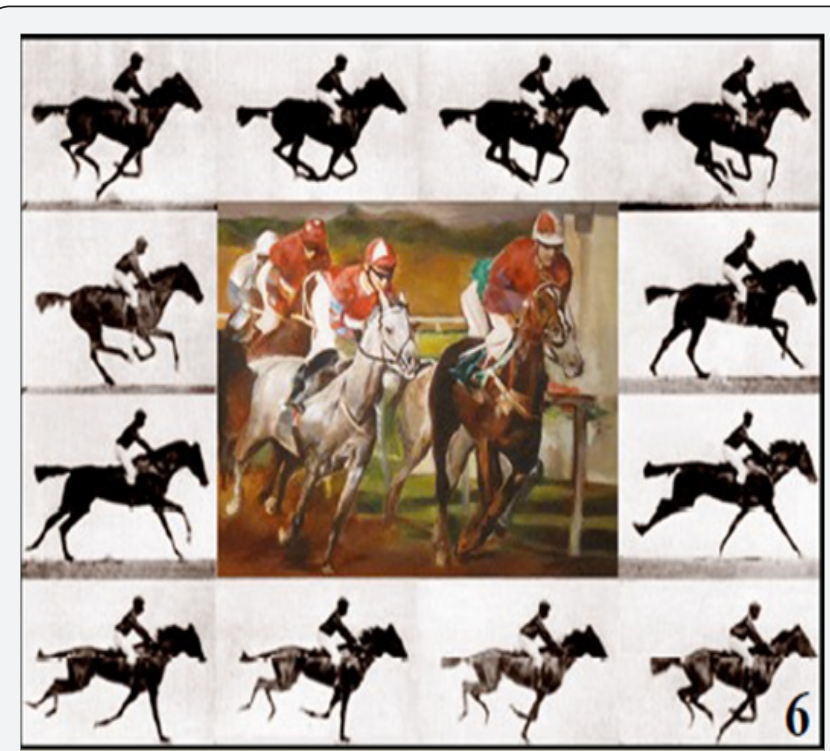

Figure 6: Motion due to gravity.

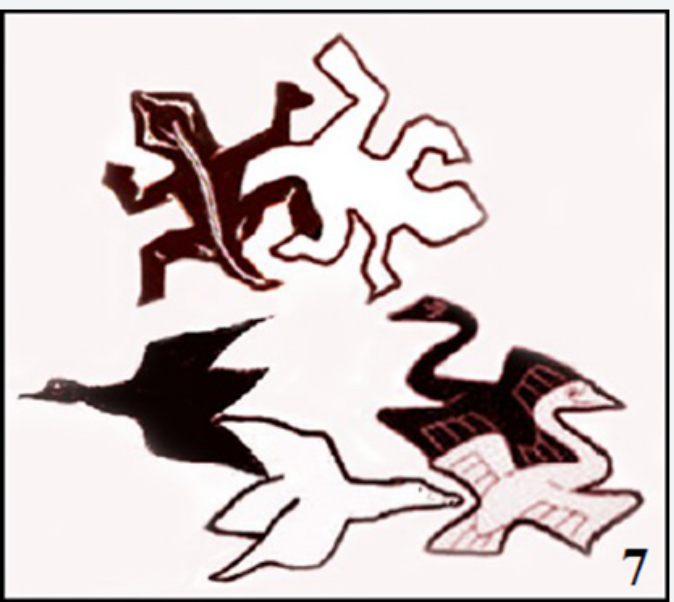

Figure 7: Reciprocating motion.

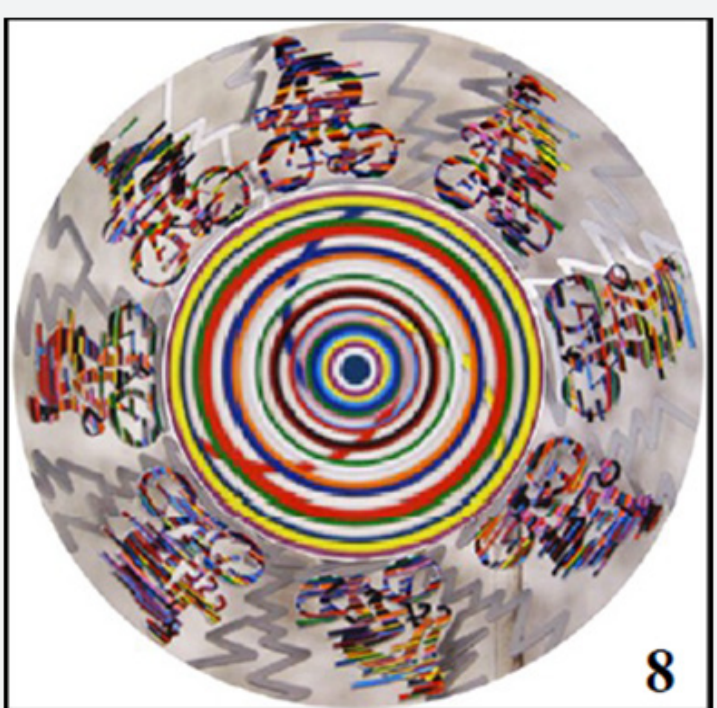

Figure 8: Rotary motion. 

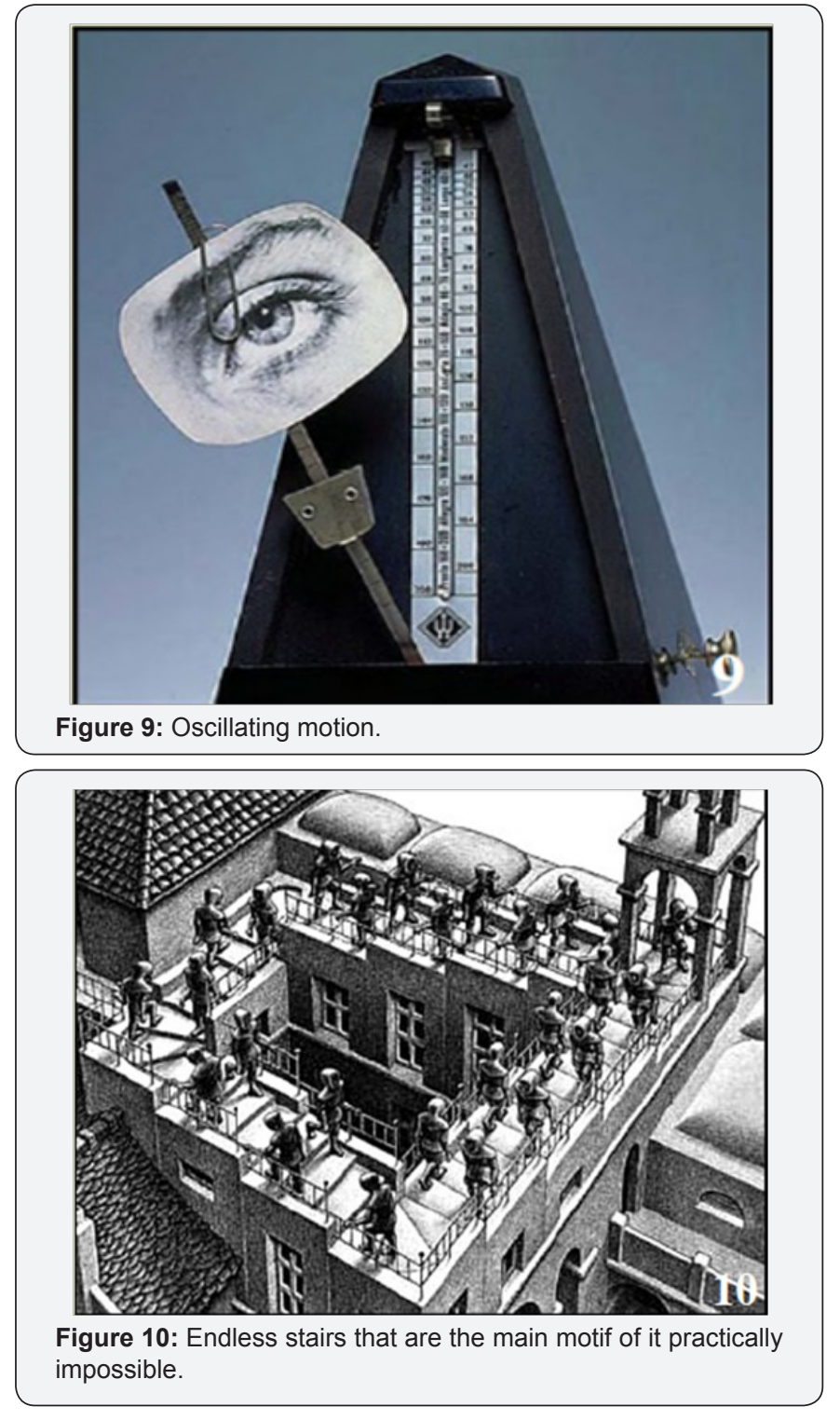

(C) Co This work is licensed under Creative

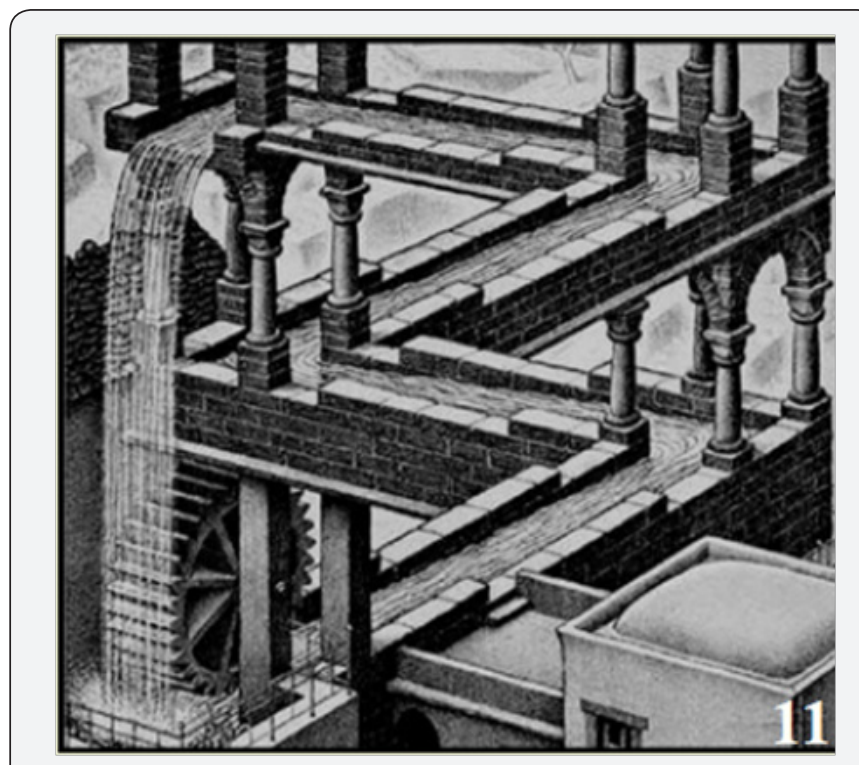

Figure 11: Waterfall.

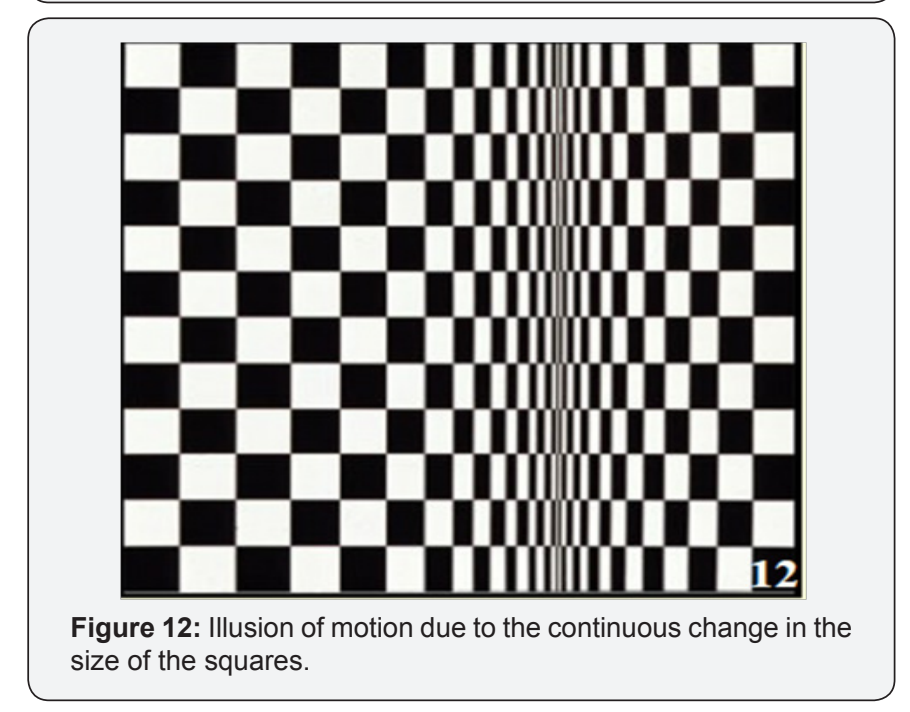

Your next submission with Juniper Publishers
will reach you the below assets
- Quality Editorial service
- Swift Peer Review
- Reprints availability
- E-prints Service
- Manuscript Podcast for convenient understanding
- Global attainment for your research
- Manuscript accessibility in different formats
( Pdf, E-pub, Full Text, Audio)
- Unceasing customer service
Track the below URL for one-step submission
https://juniperpublishers.com/online-submission.php

